\title{
EKSISTENSI PEREMPUAN DALAM NOVEL DRUPADI \\ KARYA SENO GUMIRA AJIDARMA: \\ KAJIAN EKSISTENSIALISME SARTRE \\ (The Existence of Women in Drupadi Novel by Seno Gumira Ajidarma: Sartre's Existentialism Study)
}

\author{
Heny Anggreini \\ Universitas Gadjah Mada \\ Bulaksumur Yogyakarta, Indonesia \\ Pos-el: anggreiniheny@yahoo.com
}

(Diterima Tanggal: 11 Oktober 2019; Direvisi Akhir Tanggal: 12 November 2019;

Disetujui Tanggal: 11 Desember 2019)

\begin{abstract}
This research aims to investigate a woman's role for the husband, family, and society in a literary work as an effort to free a woman from culture and tradition constructions, which always oppressing. That aim emerges due to the imbalance that Seno Gumira Ajidarma created a female character in his work, which wrote in 1984 with a different delineation, that is Drupadi story: a woman's voice is heard and considered; a woman who has five husbands, however, what happens in society is a woman as a human who is dominated by men (masculine), moreover, in Indonesia polyandry is not allowed. The problem is examined by using Sartre's existentialism which views a woman as a human who thinks and is conscious of her freedom and does not accept anything as a gift. The result is a woman's existence that is portrayed by the author through Drupadi character is successfully done that is when a woman's voice is heard in men's space (warfare) to contribute about her thought. However, the author also brings down a woman's respectability which he has built since the beginning of the story through Drupadi character. It happens due to the author has been constructed by the thought made by society for a woman that a woman below man and should follow the rules that restraint themselves.
\end{abstract}

Keywords: domination; Sartre's existentialism; woman

\begin{abstract}
Abstrak
Penelitian ini bertujuan untuk menyelidiki peran perempuan bagi suami, keluarga, dan masyarakat dalam karya sastra sebagai upaya membebaskan perempuan dari konstruksi-konstruksi adat dan budaya yang selalu mengopresi. Tujuan tersebut muncul karena melihat adanya kesenjangan, yaitu Seno Gumira Ajidarma menciptakan tokoh perempuan dalam karangannya yang ditulis pada tahun 1984 dengan 'wajah' berbeda, yaitu kisah Drupadi: suara perempuan didengar dan dipertimbangkan; serta perempuan yang bersuami lima. Akan tetapi, yang terjadi di dalam masyarakat adalah perempuan sebagai sosok yang didominasi oleh kaum laki-laki (maskulin), bahkan di Indonesia poliandri tidak dibenarkan. Permasalahan tersebut dikaji menggunakan eksistensialisme Sartre yang memandang bahwa perempuan adalah manusia yang berpikir dan sadar akan kebebasan dirinya dan tidak begitu saja menerima suatu hal sebagai pemberian. Berdasarkan hal itu, hasil penelitian adalah eksistensi perempuan yang digambarkan oleh pengarang melalui tokoh Drupadi, berhasil dilakukan, yaitu perempuan diterima suaranya dalam ruang laki-laki (peperangan) untuk menyumbangkan hasil pemikirannya. Namun, pengarang juga menjatuhkan kehormatan perempuan, yang telah dibangunnya dari awal cerita melalui tokoh Drupadi. Hal ini karena pengarang telah terkonstruksi oleh pemikiran yang dibuat oleh masyarakat bagi perempuan bahwa perempuan berada di bawah laki-laki dan harus mengikuti aturan-aturan yang mengekang dirinya.
\end{abstract}

Kata kunci: dominasi; eksistensialisme Sartre; perempuan 


\section{PENDAHULUAN}

Drupadi, sebuah novel karya Seno Gumira Ajidarma, diterbitkan pada tahun 2017. Novel ini memuat 10 bab, bab $1-5$ telah dimuat bersambung oleh majalah Zaman pada Januari sampai Desember 1984. Bab selanjutnya, yaitu 6-10 dimuat di beberapa media cetak, seperti: Kompas, Republika, Media Indonesia, Suara Pembaruan, dan Suara Merdeka pada tahun 2001 (Tempo.co, 2017).

Novel ini mengangkat tokoh perempuan, yaitu Drupadi. Drupadi merupakan salah satu tokoh di epos Mahabharata, yaitu istri dari lima Pandawa. Akan tetapi, pada karya novel ini Seno melihat kisah Mahabharata melalui kaca mata sastra Jawa. Epos India ini telah menjadi mitologi Jawa karena memberikan pengaruh besar bagi sastra Jawa, terlihat dari seringnya cerita yang dibawakan dalam pertunjukan wayang mengambil kisah Mahabharata (Fang, 2011: 99).

Tokoh Drupadi digambarkan sebagai perempuan yang 'bebas' dan hadir dalam konstruksi atas kemauannya sendiri. Sebagai perempuan, Drupadi tidak menerima secara legowo tentang konsep-konsep yang dilekatkan pada perempuan. Justru, Drupadi bersuara ketika melihat maupun mengalami ketidakadilan dan ketertindasan pada perempuan.

Hal tersebut yang disoroti oleh Seno karena masih ada perempuan yang menerima konsep tentang perempuan sebagai kodratyang tidak boleh dipertanyakan. Perempuan dituntut untuk menjadi seperti yang diinginkan masyarakat dan keluarga. Perempuan tidak lagi melakukan dan menjadi apa yang ia inginkan, tetapi melakukan apa yang diinginkan oleh orang lain terhadapnya.

Seno menggambarkan sosok perempuan yang berbeda pada tahun ditulisnya cerita melalui tokoh Drupadi, seperti perempuan memiliki pengaruh besar bagi suaminya (lima pandawa), perempuan memiliki lima suami yang di Indonesia tidak dibenarkan, perempuan yang bebas bersuara, perempuan yang memiliki hak atas dirinya sebagai perempuan
(Maulana, 2017). Seno mengangkat kisah yang bertentangan dengan budaya masyarakat Indonesia, yang pada masa diterbitkannya secara bersambung pada tahun 1984, perempuan tidak memiliki suara penuh atas dirinya sendiri. Perempuan masih terbelenggu dalam ruang domestik. Sebagian perempuan masih berusaha untuk bergerak mencari dan mempertahankan posisinya di masyarakat.

Seno mengajak pembacanya untuk berpikir, berimajinasi, dan mempertanyakan sosok perempuan seperti tokoh Drupadi yang bebas. Perempuan yang menggunakan haknya untuk melakukan pembalasan atas penghinaan yang diterima perempuan. Perempuan yang berusaha melawan nasib, yaitu nasib perempuan yang direndahkan, dihina, dan selalu berada di kelas dua-yang nasib tersebut adalah bagian dari kontruksi masyarakat.

Drupadi yang mulai ditulis Seno pada tahun 1984 ini, diwacanakan bahwa tokoh Drupadi adalah perempuan yang bebas dan dihargai suaranya atau pendapatnya oleh para suaminya, lima Pandawa. Drupadi menolak penindasan dan penghinaan terhadap perempuan. Pada tahun yang sama, Indonesia menandatangani Konvensi CEDAW (The Convention on the Elimination of All Froms of Discrimination Against Women), yaitu kesepakatan internasional untuk menghapus segala bentuk diskriminasi terhadap kaum perempuan. Pada 24 Juli 1984 Indonesia telah meratifikasinya melalui UU RI No. 7 Tahun 1984 (Komnas Perempuan, 2017).

Kondisi di atas dapat dikatakan bahwa perempuan-perempuan Indonesia mengalami kekerasan oleh kaum dominan, dan sebagai seorang penulis, Seno melihat kesenjangan dalam masyarakat bahwa ruang-ruang didominasi oleh maskulin dan menempatkan perempuan sebagai tersubordinat, sebagai suatu hal yang perlu dikritisi dengan melahirkan karya Drupadi. Oleh karena itu, Seno menciptakan tokoh perempuan, Drupadi, dengan wajah yang berbeda, yaitu 'suara' perempuan didengar, ia bersuami lima pandawa (ksatria), dan ia 
memegang 'tangan' kelima suaminya, yang di Indonesia, poliandri tidak dibenarkan dan lakilaki yang memiliki kendali.

Berdasarkan hal tersebut persoalan yang diangkat adalah pertama, bagaimana perempuan menggunakan haknya untuk bereksistensi dalam novel Drupadi karya Seno Gumira Ajidarma? Kedua, bagaimana perempuan bereksistensi sebagai istri bersuami lima dijelaskan Seno GumiraAjidarma melaluinovelDrupadi? Ketiga, apa yang ingin diperjuangkan Seno sebagai pengarang laki-laki, yang membahasakan perempuan dalam novel Drupadi? Berdasarkan masalah tersebut tujuan dari penelitian ini adalah untuk menyelidiki peran perempuan bagi suami, keluarga, dan masyarakat dalam upaya membebaskan perempuan dari tuntutan masyarakat sehingga yang dilakukan perempuan berdasarkan yang diinginkannya.

\section{KERANGKA TEORI}

Eksistensi adalah melakukan suatu hal berdasarkan pemikiran diri sendiri. Maka disebutkan bahwa eksistensi mendahului esensi, yang artinya seseorang harus ada terlebih dahulu, kemudian mengetahui dirinya sendiri dan dunia yang dihadapinya, dengan demikian manusia dapat mendefenisikan dirinya. Manusia akan berharga apabila melakukan sesuatu didasari pada dirinya sendiri (Panjaitan dalam Geleuk dkk., 2017: 225).

Manusia adalah manusia itu sendiri yang memulai hidup dari yang tidak 'apa-apa' menjadi manusia yang memiliki 'apa-apa' yang menjadikan manusia ada adalah dirinya sendiri, ia adalah apa yang dianggap sebagai dirinya, tetapi ia adalah apa yang ia ingini, dan ketika ia menerima diri setelah mengada - ketika apa yang ia ingini terwujud setelah ia meloncat ke dalam eksistensinya. Manusia adalah bukan apaapa selain apa yang ia buat dari dirinya sendiri. Itu adalah prinsip pertama eksistensialisme. Hal itu disebut "subjektivitas", apabila ingin menggunakan kata untuk mengkritik diri (Sartre, 2002: 44-45).
Jean-Paul Sartre mendefenisikan eksistensi sebagai humanisme. Baginya, eksistensialis adalah percaya dan bertindak berdasarkan dalil. Manusia tidak akan menjadi apa-apa sampai ia menjadikan hidupnya 'apa-apa'. Manusia adalah ia yang melakukan sesuatu untuk dirinya sendiri (Udasmoro, 2017: 94).

Etre pour autrui, "ada untuk orang lain" artinya manusia tidak memiliki kebebasan atas dirinya. Manusia hidup berdasarkan orang lain. $L$ 'autre, orang lain mengurangi ruang kebebasan manusia untuk menentukan dirinya sendiri. Ketika orang lain menyebut 'cantik atau jelek, itu adalah akibat adanya $L$ 'autre, pandangankeinginan orang lain terhadap diri. Ini membuat manusia tidak bisa lepas dari orang lain yang pada dasarnya adalah neraka (Wibowo, 2011: 26-27). Sartre menyebutkan bahwa orang lain adalah neraka-mengekang, membelenggu setiap kebebasan yang seharusnya bisa dilakukan manusia itu sendiri (Wibowo, 2011: 32). Manusia menjadi manusia lewat aktivitas parasitisnya terhadap semua bentuk tatapan orang lain yang mau mengobjekkan dirinya. Selayaknya, manusia ada untuk dirinya sendiri (pour soi), sebuah kebebasan, tidak terbatas, yang termanifestasikan dalam parasitisme pelubangan kepejalan pengobjekan dirinya (ensoi). Lewat kebebasan itu manusia menjadikan dirinya sendiri (Wibowo, 2011: 33).

Tatapan mata orang lain menjadikan manusia 'objek'. Sartre menyebut bahwa manusia ditentukan oleh cara pandang orang lain. Ini membuat ada yang berkurang dalam diri manusia, yaitu kebebasan. Kebebasan adalah diri manusia yang tidak ditentukan, yang tidak diembel-embeli dengan apapun. Sartre menyebutnya pour soi "ada untuk dirinya sendiri” (Wibowo, 2011: 29-30).

Teori sastra Sartre memiliki kedekatan gagasan dengan being and nothingness. Kebebasan manusia adalah kesadaran bahwa dirinya adalah subjek yang membedakan diri dari objek. Manusia yang lain akan selalu berusaha untuk mengobjekkan apa pun yang dipandangnya. Kebebasan manusia 
menciptakan dunia. Setiap manusia ingin menjadi subjek tunggal di dunia ini sehingga terjadi tabrak menabrak untuk menjadi yang terunggul. Untuk itu, di hadapan yang lain aku adalah objek. Manusia hidup dalam kecemasan antara menghidupi untuk kebebasan (menjadi etre pour soi) atau menolak untuk menghidupi kebebasan (etre en soi) (Wibowo, 2011: 94).

Sartre memiliki konsep, yaitu etre-poursoi, etre-en-soi, dan mauvaise foi. Konsep etre-pour-soi adalah hidup untuk kebebasan. Manusia melakukan sesuatu untuk kebebasan dirinya (kesadaran untuk dirinya sendiri), bukan karena 'ingin' orang lain menjadi yang 'diinginkan' oleh orang lain sedangkan konsep etre-en-soi adalah menolak hidup dalam kebebasan. Artinya, manusia menerima dengan begitu saja atas kehidupan yang diberikan. Manusia menerima semua yang terjadi dalam hidupnya sebagai sebuah pemberian sedangkan keadaan melarikan diri dari kebebasan oleh Sartre disebut mauvaise foi (Udasmoro, 2017: 94-95).

Mauvaise foi membimbing manusia hidup dalam kepasifan, inersia, penarikan diri, dan kekalahan. Konsep ini, manusia berpura-pura telah cukup diri (menjadi being in itself) seolah yang lain tidak dapat menyentuhnya. Untuk lari dari tanggung jawab kebebasan, manusia dapat menghayati hidup dalam ada bagi yang lain (being for others) - manusia hidup berdasarkan keinginan orang lain (Wibowo, 2011: 94).

\section{METODE}

Penelitian ini dilakukan dengan mengaplikasikan metode penelitian deskriptif kualitatif, yang mengarah pada analisis isi (Udasmoro, 2012: 36). Penelitian ini menggunakan objek material novel Drupadi karya Seno Gumira Ajidarma, yang datadatanya akan dikumpulkan dengan membaca secara berulang dan teliti. Selanjutnya dilakukan proses analisis data berdasarkan pertanyaan penelitian dengan menggunakan teori eksistensialisme Sartre untuk melihat eksistensi perempuan dalam novel.

\section{PEMBAHASAN}

Konsep eksistensialisme yang dikemukakan oleh Sartre digunakan untuk mengupas Novel Drupadi yang dikarang oleh Seno Gumira Ajidarma. Novel ini mencerminkan sikap perempuan melalui tokoh Drupadi yang tidak hidup untuk memenuhi aturan-aturan yang dibuat untuknya, akan tetapi untuk bersuara menyatakan setiap pemikirannya.

\section{Tokoh Drupadi Menggunakan Haknya}

Drupadi merupakan perempuan yang menggunakan haknya. 'Hak' merupakan bentuk eksistensi perempuan.

Seperti yang digambarkan Seno dalam novel Drupadi, Drupadi sebagai tokoh utama yang berperan sebagai perempuan 'bebas' tidak hidup berdasarkan pemberian dari dewa, tetapi hidup atas keinginan dirinya. Oleh karena itu, ia tidak menerima penghinaan yang dilakukan oleh Kurawa.

Dursasana, saudara Duryudhana, menyeret-menarik rambut Drupadi hingga terurai-melemparkannya ke lantai untuk tunduk kepada Duryudhana. Di hadapan kelima suaminya, Pandawa, Drupadi dihina, bahkan diperkosa di atas meja judi oleh seratus Kurawa. Kurawa yang terakhir yang memperkosa Drupadi adalah Dursilawati, seorang perempuan. Melalui itu, tergambar bahwa Dursilawati adalah sosok perempuan yang tidak memiliki kebebasan atas dirinya. Ia hidup berdasarkan perintah dan konstruksi yang dibuat oleh saudarasaudaranya. Drupadi yang telah dihina oleh Kurawa, tidak mendapatkan pembelaan, baik oleh Kresna maupun kelima suaminya sebab Pandawa telah mempertaruhkan segalanya di meja judi, termasuk kehormatan — kemerdekaan diri mereka sendiri. Walaupun begitu, Seno melakukan pembalikan cerita: Drupadi yang telah diperkosa akan tetap suci. 
"Pandawa, suami-suamiku yang lima, mengapa kalian diam saja melihat istri kalian dihina begini rupa," katanya. "Yudhistira suamiku yang agung, siapakah kiranya dimuka bumi ini mampu dan tega, di meja perjudian mempertaruhkan istrinya, ksatria Indraprastha?" (Ajidarma, 2017: 61)

Berdasarkan dialog di atas, terjelaskan bahwa perempuan adalah konstruksi yang indah bagi laki-laki. Konstruksi tersebut kabur di penglihatan perempuan sehingga tanpa disadari yang diterima adalah bentuk opresi. Seperti yang diungkapkan oleh Mary (Watkins, dkk, 2007: 18), femininitas adalah sebuah konstruksi. Perempuan dilahirkan setara dengan laki-laki, namun dididik untuk menjadi sosok yang lemah dan jinak — subordinat.

Penghinaan yang diterima oleh perempuan, yaitu tokoh Drupadi, menjadikannya sebagai perempuan lebih tangguh. Ia menggunakan haknya-meminta pembalasan atas penghinaan yang diterima sesuai dengan keinginannya. Artinya, tokoh Drupadi melakukan sesuatu berdasarkan kehendaknya sendiri setelah mengalami situasi tersebut-mengkritisi apa yang telah diterimanya. Drupadi membebaskan dirinya (etre pour soi) dari penghinaan dengan mencuci rambutnya menggunakan darah Dursasana. Ia tidak melihat darah itu sebagai balasan atas dendamnya pada Dursasana, melainkan sebagai tirta amerta yang bercahaya. Ia ingin melengkapi putaran roda kehidupan bahwa setiap orang berhak atas keadilan.

“Aku Drupadi, seorang perempuan, terus terang menghendaki darah Dursasana, untuk memberi pelajaran bagi penghinaan." (Ajidarma, 2017: 107)

Drupadi adalah tokoh yang tegas. Ia tidak hidup berdasarkan kehendak orang lain, tetapi berdasarkan pemikiran dan kesadarannya bahwa hidup bukan suatu pemberian. Drupadi menyadari bahwa untuk menjadi manusia adalah melakukan sesuatu untuk dirinya sendiri- menjadikan hidupnya memiliki arti bukan tuntutan orang lain. Kondisi tersebut membuat dia menjadi orang yang bebas. Ia bersuara untuk membebaskan perempuan dari penghinaan. Perempuan memiliki hak untuk memperoleh keadilan. Dengan begitu, orang-orang akan tahu bahwa kehidupan di dunia menempatkan perempuan pada ruang yang sama. Hanya saja, masyarakat, budaya, tradisi, mengikat tangan dan kaki perempuan dengan aturan-aturan yang disebut sebagai kodrat, untuk diterima sebagai pemberian, yang nyatanya aturan-aturan itu merugikan perempuan.

"Dunia ini penuh dengan kekerasan, Kresna. Terutama aku, perempuan, selalu jadi korban." (Ajidarma, 2017: 108)

Perempuan akan selalu menjadi korban bagi kaum laki-laki untuk melanggengkan kekuasaan mereka. Perempuan menjadi korban karena kontruksi yang diciptakan laki-laki agar perempuan selalu meminta pertolongan kepada laki-laki. Keinginan untuk selalu membutuhkan laki-laki-tidak bisa lepas dari laki-laki, berada di bawah 'ketiak' laki-laki. Namun, Drupadi tidak menerima itu. Perempuan memiliki hak yang sama. Mampu bertindak-berbuat. Perempuan juga bisa berada di ruang yang laki-laki tempati. Perempuan tidak selamanya berada di ruang domestik yang sengaja dirancang untuk menutup mata perempuan dari dunia publik.

Drupadi ikutmengembara bersama kelima suaminya. Bahkan, pendapatnya diterimasuaranya didengar oleh kelima suaminya. Ini menunjukkan bahwa pada tahun 1984, bab satu sampai lima, cerita ini sudah terbit di majalah Zaman, pengarang mulai memunculkan pandangan-pandangan tentang perempuan yang memiliki hak untuk kebebasannya tidak selalu tunduk pada aturan-aturan atau perkataan laki-laki.

"Kresna, engkau sungguh pandai bicara. Tapi engkau belum pernah menjadi korban. .... Aku adalah korban, dan aku menggunakan hak diirku sebagai 
korban untuk menjawab nasibku dengan kemarahan. .... Aku sudah menjadi korban, dan dari seseorang yang menjadi korban, engkau memintanya berjiwa besar? Apakah itu tidak terlalu berlebihan? Biarlah resi Bhisma atau Karna atau Yudhistira berjiwa besar, tapi aku Drupadi, seorang perempuan, menggunakan hak diriku sebagai korban untuk melakukan pembalasan." (Ajidarma, 2017: 108)

Drupadi tidak menerima nasib yang datang kepadanya begitu saja. Segala sesuatunya perlu diperjuangkan - dipertanyakan. Hanya manusia itu sendiri yang mampu menjadikan dirinya ada dan memperoleh kebebasan (etre pour soi). Sementara orang lain hanya akan menjatuhkan dengan embel-embel yang sengaja dibuat untuk menghancurkan karena orang lain juga ingin menjadi subjek. Segalanya bertarung — saling berbenturan. Laki-laki ingin posisinya aman karena kehadiran perempuan ke ruang publik, dianggap akan mempersempit posisi mereka.

"Aku tidak akan tidur dengan seorang pun dari Pandawa selama ia (Dursasana) belum terbunuh. Aku mau semua Kurawa itu mati, dan aku akan mengeramas rambut ini dengan darah Dursasana." (Ajidarma, 2017: 99)

Kutipan tersebut menjelaskan bahwa perempuan memiliki hak atas dirinya. Ia bisa memilih_bebas menetukan yang diinginkannya. Ia bisa menolak. Tidak begitu saja menerima permintaan selama dirinya tidak menyukai itu. Perempuan memiliki kebebasan atas seluruh hidupnya.

\section{Eksistensi Drupadi sebagai Istri Bersuami Lima Pandawa}

Tokoh Drupadi digambarkan begitu sangat cantik oleh pengarang, yaitu kecantikannya melebihi kecantikan mimpi. Kecantikan ini dikonstruksi oleh dewa bahwa tidak ada perempuan yang kecantikannya melebihi Drupadi. Bahkan, Drupadi dijelaskan, diciptakan dari sekuntum bunga teratai yang sedang merekah. Seperti bunga teratai yang tidak akan hilang kecantikannya walau tumbuh di lumpur, begitu pula pengarang menggambarkannya. Drupadi akan tetap suci sekalipun di meja judi ia telah diperkosa oleh seratus Kurawa secara bergantian.

Drupadi, menunjukkan eksistensinya sebagai istri dari lima pandawa adalah dengan suaranya yang selalu didengar. Ucapannya semacam perintah yang harus dilaksanakan oleh suaminya. Seperti keinginan Drupadi yang menyuci rambutnya dengan darah Dursasana. Permintaan Drupadi digenapkan oleh Bima. Bima meminum darah Dursasana, sedangkan Drupadi menyiram rambutnya. Selain itu, Drupadi menginginkan kematian seratus Kurawa. Permintaannya itupun digenapkan oleh para Pandawa sehingga terjadilah perang besar, yaitu perang Bharathayudha. Kecantikan yang dimiliki Drupadi tersebut tidak sepenuhnya mengekang Drupadi, justru kecantikan itu adalah kekuatannya. Untuk memperolehnya, para kesatria (laki-laki) harus berusaha-bertarung dengan mengikuti sayembara. Laki-laki yang perkasa, yang akan memperoleh dirinya. Drupadi digambarkan sebagai perempuan yang memiliki hak penuh atas diri dan kebebasannya. Ia memiliki kehendaknya sendiri, dan suaranya didengar.

Namun, Drupadi suatu ketika kehilangan anak-anaknya, ayahnya, dan saudaranya yang dibunuh oleh Aswattama, anak guru Drona. Drupadi menjadi perempuan yang merasa bahwa kehidupan sedang mempermainkannya. Drupadi secara tidak sadar menjadi perempuan yang menerima kodrat bahwa dewa tidak menginginkannya bahagia (mauvaise foi). Ia menjadi sosok yang lemah bahkan ia tidak lagi menganggap dirinya sebagai Drupadi.

"Aku bukan Drupadi. Aku tak tahu siapa diriku lagi. perasaanku hancur, tubuhku mengambang, jiwaku melayang-layang. .... O Yudhistira, katakanlah pada Arjuna agar merampas mutiara di dahi Aswattama. Biarlah aku menjadi perempuan yang 
penuh dengan dendam, jika memang suaratan menghendakinya demikian." (Ajidarma, 2017: 118-119)

Kutipan itu menunjukkan bahwa Drupadi mengalami kondisi yang tidak stabil. Kehancuran hatinya menjadikannya perempuan yang menerima takdir - kodrat yang diberikan kepadanya (etre en soi). Drupadi menerima segala takdir-kodrat yang diberikan kepadanya, tetapi keinginannya untuk balas dendam adalah salah satu bentuk kebebasannya (etre pour soi). Membalaskan dendam adalah bentuk kebebasan yang dirasakan oleh Drupadi. Ia akan terbebas dari segala kesedihan dan rasa sakit karena hilangnya keluarga. Peperangan sudah mengambil banyak kebahagiaan. Dengan balas dendam, ia merasa bebas.

\section{Pesan Seno Gumira Ajidarma: dalan Drupadi}

Seno sebagai pengarang laki-laki, sudahkah sepenuhnya mendukung Drupadi (perempuan)?

Ah, kalau saja perempuan bisa memilih suaminya sendiri! (Ajidarma, 2017: 8)

Ini menjadi sebuah pertanyaan yang sulit karena Seno adalah pengarang lakilaki. Mampukah ia membahasakan bahasa perempuan? Bahasa menciptakan jarak bagi perempuan maupun laki-laki, namun bahasa lebih cenderung memenjarakan perempuan (Sugihastuti dan Dwi, 2010: 1). Situasi tersebut menurut Dorothy Richardson (dalam Sugihastuti dan Dwi, 2010: 3) dikarenakan laki-laki dan perempuan berbicara dengan bahasa yang berbeda. Laki-laki tidak bisa memahami bahasa perempuan sehingga perempuan menyesuaikan pola bahasanya dari bahasa perempuan menjadi bahasa laki-laki.

Kutipan di atas semacam ungkapan Seno kepada dirinya sendiri maupun kepada pembaca yang secara tidak langsung, ia membahasakan bahwa perempuan seharusnya dijodohkan. Pasangannya dipilihkan. Secara tidak sadar, Seno mengaminkan tradisi dan halhal yang diciptakan untuk perempuan.
Apabila ditilik kembali, penggambaran Seno terhadap tokoh Drupadi yang bebas bersuara adalah bentuk emansipasi perempuan, namun di sisi yang lain untuk menjatuhkan sosok perempuan melalui tokoh Drupadi bahwa dunia akan porak poranda dengan ikut sertanya perempuan dalam peperangan (pekerjaan yang biasa dilakukan laki-laki)_perempuan yang masuk ke dalam 'ruang' laki-laki akan menghancurkan struktur atau sistem yang sudah ada.

Berkali-kali tokoh Drupadi berbicaramenggunakan haknya sebagai manusia yang memiliki kesetaraan, bahkan Seno mendukung melalui narasi-narasi, tetapi, berulang pula Seno 'mengikat' Drupadi seperti ditimang nasibnya oleh para Pandawa (tentang siapa yang akan menikah dengan Drupadi). Dialog Kresna dengan Drupadi:

"Baratayudha adalah sebuah penebusan, Drupadi, .... Perang ini penuh perlambangan. Siapakah yang lebih jahat, Drupadi, Dursasana yang menelanjangimu atau Bima yang menghirup darah Dursasana? Perang ini adalah sebuah pertanyaan. Apakah jalan kekerasan para kesatria bisa dibenarkan?" (Ajidarma, 2017: 105-107)

Dan

"Ingatlah Drupadi, bukan hanya dikau seorang yang menderita. Pandawa juga kehilangan saudaranya, seratus Kurawa dan Resi Bhisma tercinta. Utari yang hamil tua juga kehilangan suaminya. Tak ada yang menang dalam peperangan. Tak akan pernah ada." (Ajidarma, 2017: 121)

Penggalan-penggalan dialog Kresna (laki-laki) tersebut, bisa dikatakan sebagai suara laki-laki terhadap perempuan. Penderitaan yang selama ini dieluh-eluhkan perempuan tidak sepenuhnya benar karena laki-laki juga mengalami penderitaan ketika perang (baca: hal-hal di 'ruang' laki-laki sendiri) - banyak hal yang dikorbankan laki-laki. 


\section{PENUTUP}

Kecantikan perempuan yang digambarkan Seno melalui tokoh Drupadi adalah kecantikan yang diciptakan laki-laki, yaitu Seno sebagai pengarang. Seno secara tidak sadar telah 'menjatuhkan' Drupadi, seorang perempuan, yang setiap dialognya berisi kebebasankekuatan tetapi pengarang selihai apapun bermain kata-kata, tidak akan lepas dari dirinya. Ia akan kembali kepada pemikirannya, tanpa disadari. Seno mewacanakan poliandri pada masa 1984 belum ada, bahkan sampai sekarang tidak diterima di Indonesia. Seno mengangkat perempuan, namun juga menjatuhkan perempuan tetapi karena Seno sendiri sudah terkontruksi oleh pemikiran-pemikiran yang dibuat oleh masyarakat bagi perempuan bahwa perempuan harus mengikuti aturan-aturan yang mengekang dirinya.

Seno ingin membebaskan perempuan dari mauvoise foi, hal itu berhasil dalam setiap dialog-dialog yang ada. Drupadi mewacanakan perempuan. Namun, di samping itu, maskulin pengarang terlihat. Bagaimana pun, Seno adalah pengarang laki-laki yang tidak akan bisa sepenuhnya membahasakan bahasa perempuan karena perempuan memiliki bahasa untuk membahasakan dirinya sendiri.

\section{DAFTAR PUSTAKA}

Ajidarma, Seno Gumira (2017), Drupadi: Perempuan Poliandris. Jakarta: PT Gramedia Pustaka Utama

Fakih, Mansour (1997), Analisis Gender dan Transformasi Sosial. Jakarta: Pustaka Pelajar.

Fang, Liaw Yock. (2011), Sejarah Kesusastraan Melayu Klasik. Jakarta: Yayasan Pustaka Obor Indonesia

Geleuk, Maria Benga (ed.) dkk. (2017) Perjuangan Tokoh Perempuan dalam Novel Tanah Tabu Karya Anindita S. Thayf: Kajian Feminisme Eksistensialis. Jurnal Ilmu Budaya, Vol 1 No. 3 (221-232)
Komnas Perempuan. (2017, Juli). Siaran Pers Komnas Perempuan, Catatan Komnas Perempuan 33 Tahun Ratifikasi Konvensi CEDAW di Indonesia: "Implementasikan CEDAW dalam Pemenuhan Hak Perempuan Korban Kekerasan" Jakarta. Diambil dari http:// www.komnasperempuan.go.id/readnews-siaran-pers-komnas-perempuancatatan-komnas-perempuan-33-tahunratifikasi-konvensi-cedaw-di-indonesia (diakses pada tanggal 9 November 2019).

Maulana, Arief. (2017, Maret). Melihat Sosok Drupadi dalam Perspektif Seno Gumira Ajidarma. Diambil dari http://www.unpad. ac.id/2017/03/melihat-sosok-drupadidalam-perspektif-seno-gumira- ajidarma/ (diakses tanggal 20 Februari 2019).

Sartre, Jean Paul. (2002), Eksistensialisme dan Humanisme. (Terjemahan Yudhi Murtanto). Yogyakarta: Pustaka Pelajar

Sugihastuti dan Dwi Purwanti (2010), Membongkar Androsentrisme dalam Prosa Lirik. Yogyakarta: Lembah Manah Tempo.co. (2017, Februari). Seno Gumira Luncurkan Novel Drupadi, Baca Wawancara Ini. Diambil dari https:// seleb.tempo.co/read/848296/senogumira-luncurkan-novel-drupadi-bacawawancara-ini/full\&view $=$ ok (diakses tanggal 20 Februari 2019).

Udasmoro, Wening. (2012), Buku Ajar Pengkajian Sastra: Bagaimana Meneliti Sastra? Mencermati Metodologi Dasar dalam Meneliti Sastra. Yogyakarta: Gadjah Mada University Press.

------ (2017) Dari Doing ke Undoing Gender: Teori dan Praktik dalam Kajian Feminisme. Yogyakarta: Gadjah Mada University Press.

Watkins, Susan Alice (ed.) dkk. (2007), Feminisme untuk Pemula. Yogyakarta: Resist Book.

Wibowo, A. Setyo (ed.) dkk. (2011), Fils afat Eksistensialisme Jean Paul Sartre. Yogyakarta: Kasinus. 